\section{TERRITORIAL FORCE.}

In a printed reply circulated with Parliamentary papers on Feb. 7th, Mr. Haldane has informed Mr. Crooks that, as has already been announced in THE LANCET of Dec. 14th, 1907, p. 1718, it is proposed to appoint Surgeon-Lieutenant. Colonel (Hon. Surgeon-Colonel) P. B. Giles one of the medical officers of the 1st Herefordshire Rifle Volunteers, to the office of principal medical officer of one of the London divisions of the Territorial Force. He is (adds Mr. Haldane) commandant of the Volunteer Ambulance School in London, an institution which has been most successful in training a large proportion of the Volunteer medical officers. He resides near London. Seniority was not the determining factor in selecting officers for the appointments, but those officers best fitted to carry out the work were chosen, seniority being given its due weight.

DEaths IN THE SERVICES.

Inspector-General of Hospitals and Fleets Sir John Denis Macdonald, K C.B., F.R S., R.N., on Feb. 7th, at Southall, aged 82 years. He entered the service as surgeon in 1849, was promoted to staff-surgeon in 1859, to fleet-surgeon in 1866 , to deputy-inspector-general in 1875 , to inspectorGeneral in 1880, and retired six years later.

Surgeon-General William Henry Rean, Indian Army (retired), on Feb. 6th, aged 81 years. He entered the East India Company's service in 1853, and in 1857 served with the Madras Fusiliers in the attempted relief of Cawnpore. After the massacre he was appointed chief medical officer in charge of the standing hospital at Cawnpore, where he contracted cholera. After serving as deputy-surgeon-general at Kampti he retired in 1881.

The Times states that about 100 boys belonging to the training ship Impregnable at Devonport are in hospital, the majority suffering from influenza which is very prevalent throughout the port.

A Royal Naval hospital is to be opened at Queensferry with a staff of one fleet-surgeon or staff-surgeon, one surgeon, one chief sick-berth steward, and two sick-berth attendants.

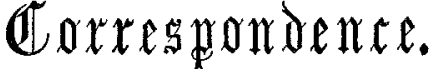

"Audi alteram partem."

\section{HOSPITAL ALMONERS. \\ To the Editor of THe LANCET.}

Sir, - In view of the letters of appeal from general practitioners and others that appear constantly in the daily papers against the deplorable abuse of the out-patients' de. partments of our London and provincial hospitals, I venture to call the attention of your readers to a system which is slowly but surely gaining ground among the hospitals of this vast metropolis. The fact that the out-patients' departments are not only centres of startling abuse but also the means of pauperising a large proportion of the working classes has been brought before the public from time to time for the last 30 years.

About 12 years ago the Royal Free Hospital, recognising the responsibility incurred in this respect, created the post of almoner. A lady, duly qualified by experience and know. ledge and being intimately acquainted with the mode of living and ways of thought obtaining amongst our poorer classes, was appointed to the post. Her duties were: 1. To interview all new patients to the hospital after such patients had been seen by a member of the staff and to investigate thoroughly each case by means of outside visitors and societies. 2. To report to the authorities all cases which were not suitable for free medical treatment. 3. To provide from the funds of the Hospital Samaritan Fund, in coöperation with outside charities, all surgical instruments, convalescence, \&c., recommended by the medical staff except in such cases where the patients or their family were able to provide such instruments and treatment themselves. 4. To ensure that the home conditions of the patients should, so far as possible, be suitable, and that the directions of the physicians or surgeons as to diet, fresh air, exercise, or rest should be carried out.

It was not long before the system I have briefly sketched resommended itself to the authorities of other hospitals and after two or three years Westminster and St. George's
Hospitals created similar posts and to-day there are no less than nine well-known hospitals where almoners are working. The system leads to economy both in the time of the staff and the expenses of the hospital and its satisfactory results may be attested by the fact that no hospital that has appointed an almoner has ever seen reason to recall its decision. The system must of necessity appeal to any hospital with a medical school in that it protects the interests of the general practitioners who have been, or are being, trained within its walls. As no patient is dismissed without the consent of the physician or surgeon who has examined the patient it will be easily seen that the interests of the medical school as to clinical material are guarded.

The daily letters of thanks and approval from outside doctors show that the general practitioners realise that a very potent method has at last been set on foot to safeguard their interests. The work of an almoner is both difficult and arduous and calls for a very special training and careful selection of candidates. A hospital almoners' council has lately been formed for the purpose of arranging the training and selection of almoners and for providing suitable candidates for London and the provinces.

It is in the hope that this letter may explain briefly the work of an almoner and thereby prove that the out-patients' departments need no longer be a cause of apprehension to the outside doctors or a centre of panperisation and abuse that I have ventured to encroach upon your valuable space. May I add that $I$ shall be pleased to give any further information on the subject either by letter or by appointment to any of your readers who may be interested in the question.

$$
\text { I am, Sir, yours faithfully, }
$$

A. S. Morse, Oapt. and Sec.

Hospital Almoners' Council, Denison House, Vauxhall Bridge-road, S.W., Feb. 11th, 1908.

\section{PLEURAL EFFUSION AND ITS TREATMENT. \\ To the Futitor of THE LANOET.}

SIR,-Dr. Harry Campbell tries, but in vain, to make the worse appear the better cause, and I should think he would make a very obstinate juryman whom the other 11 might have some difficulty in convincing. I can therefore scarcely hope to convert him from the error of his ways, so I shall not trouble much about this lost sheep, but I shall try and show the ninety and nine, who have not gone astray, the utter worthlessness of his facile pen. I shall now analyse his letter paragraph by paragraph.

First.- His little pleasantries do not trouble me much and do not cover his retreat from an untenable position in citing a condition which does not exist. He knows as well as I do that Dr. Harry Campbell is not the man to make "concessions for the purpose of humouring Sir James Barr," or anyone else. There is a very considerable difference between an adherent and a non-adherent pleura which cannot be glossed over by saying that "they did not affect one way or the other the main issue between us." The elasticity and tautness of the lung are thus readily affected, and I cannot allow Dr. Campbell to shift his position at his own convenience without exposing his retreat to $m y$ merciless flank fire. In my first letter I agreed that the elasticity and tautness of a substance are two quite different things, but the continuous tantness of the lungs depends on their elasticity and the pressure of air within them. I say so still.

Second.-In the first 12 lines he gives his whole show away and practically accepts my contention, bat his illustrations are not very happy. "It is not the elasticity of the traces attached to a wagon which causes the wagon to be pulled along." Neither is it the tautness of the traces, nor the tautness of the lungs which exerts the traction, but the force that causes and maintains the tautness. If the stress or force applied to a series of loosely connected wagons be intermittent they bump against one another, but if they be braced up and have an elastic connexion through their buffers all this bumping disappears. The elastic lungs are held against the thoracic parietes by the atmospheric pressure within the lungs, a pressure amounting to about 760 millimetres of mercury, less, under ordinary circumstances, a few millimetres of mercury due to the elasticity of the lungs and the variations in the intrapulmonary pressure during the different phases of respiration. The greatest possible fall in the intrapulmonary pressure, as in Müller's experiment, could not 